NASA/CR-2003-211824

\title{
A Preliminary Study of Ice-Accretion Scaling for SLD Conditions
}

David N. Anderson

Ohio Aerospace Institute, Brook Park, Ohio 
Since its founding, NASA has been dedicated to the advancement of aeronautics and space science. The NASA Scientific and Technical Information (STI) Program Office plays a key part in helping NASA maintain this important role.

The NASA STI Program Office is operated by Langley Research Center, the Lead Center for NASA's scientific and technical information. The NASA STI Program Office provides access to the NASA STI Database, the largest collection of aeronautical and space science STI in the world. The Program Office is also NASA's institutional mechanism for disseminating the results of its research and development activities. These results are published by NASA in the NASA STI Report Series, which includes the following report types:

- $\quad$ TECHNICAL PUBLICATION. Reports of completed research or a major significant phase of research that present the results of NASA programs and include extensive data or theoretical analysis. Includes compilations of significant scientific and technical data and information deemed to be of continuing reference value. NASA's counterpart of peerreviewed formal professional papers but has less stringent limitations on manuscript length and extent of graphic presentations.

- TECHNICAL MEMORANDUM. Scientific and technical findings that are preliminary or of specialized interest, e.g., quick release reports, working papers, and bibliographies that contain minimal annotation. Does not contain extensive analysis.

- CONTRACTOR REPORT. Scientific and technical findings by NASA-sponsored contractors and grantees.
- CONFERENCE PUBLICATION. Collected papers from scientific and technical conferences, symposia, seminars, or other meetings sponsored or cosponsored by NASA.

- SPECIAL PUBLICATION. Scientific, technical, or historical information from NASA programs, projects, and missions, often concerned with subjects having substantial public interest.

- TECHNICAL TRANSLATION. Englishlanguage translations of foreign scientific and technical material pertinent to NASA's mission.

Specialized services that complement the STI Program Office's diverse offerings include creating custom thesauri, building customized data bases, organizing and publishing research results ... even providing videos.

For more information about the NASA STI Program Office, see the following:

- Access the NASA STI Program Home Page at http://www.sti.nasa.gov

- E-mail your question via the Internet to help@sti.nasa.gov

- Fax your question to the NASA Access Help Desk at 301-621-0134

- Telephone the NASA Access Help Desk at 301-621-0390

- Write to:

NASA Access Help Desk

NASA Center for AeroSpace Information 7121 Standard Drive

Hanover, MD 21076 
NASA/CR-2003-211824

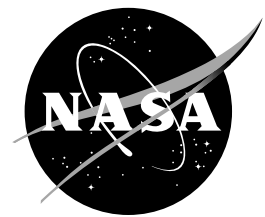

\section{A Preliminary Study of Ice-Accretion Scaling for SLD Conditions}

David N. Anderson

Ohio Aerospace Institute, Brook Park, Ohio

Prepared for the

40th Aerospace Sciences Meeting and Exhibit

sponsored by the American Institute of Aeronautics and Astronautics

Reno, Nevada, January 14-17, 2002

Prepared under Cooperative Agreement NCC3-884

National Aeronautics and

Space Administration

Glenn Research Center 


\section{Acknowledgments}

This study was jointly supported by the FAA Tech Center and the NASA Glenn Icing Branch.

The author wishes to thank Jim Riley of the FAA and Tom Bond of NASA for their support of these tests.

In addition, the IRT staff from NASA Glenn provided the skilled technical support without which these tests could not have been conducted.

This report contains preliminary findings, subject to revision as analysis proceeds.

The Aerospace Propulsion and Power Program at NASA Glenn Research Center sponsored this work.

Available from

NASA Center for Aerospace Information 7121 Standard Drive

Hanover, MD 21076
National Technical Information Service 5285 Port Royal Road Springfield, VA 22100 


\title{
A PRELIMINARY STUDY OF ICE-ACCRETION SCALING FOR SLD CONDITIONS
}

\author{
David N. Anderson* \\ Ohio Aerospace Institute \\ Brook Park, Ohio 44142
}

\begin{abstract}
$\underline{\text { Abstract }}$
Proposed changes to aircraft icing certification rules are being considered by European, Canadian and American regulatory agencies to include operation in super-cooled large droplet conditions (SLD). This paper reports results of an experimental study in the NASA Glenn Icing Research Tunnel (IRT) to evaluate how well scaling methods developed for Appendix-C conditions might apply to SLD conditions. Until now, scaling studies have been confined to the FAA FAR-25 Appendix-C envelope of atmospheric cloud conditions. Tests were made in which it was attempted to scale to a droplet $M V D$ of $50 \mu \mathrm{m}$ from clouds having droplet $M V D \mathrm{~s}$ of 175 , 120,100 and $70 \mu \mathrm{m}$. Scaling was based on the Ruff method with scale velocities found either by maintaining constant Weber number or by using the average of the velocities obtained by maintaining constant Weber number and constant Reynolds number. Models were unswept NACA 0012 wing sections. The reference model had a chord of $91.4 \mathrm{~cm}$. Scale models had chords of $91.4,80.0$ and $53.3 \mathrm{~cm}$. Tests were conducted with reference airspeeds of 100 and $150 \mathrm{kt}$ (52 and $77 \mathrm{~m} / \mathrm{s}$ ) and with freezing fractions of $1.0,0.6$ and 0.3 . It was demonstrated that the scaled $50-\mu \mathrm{m}$ cloud simulated well the non-dimensional ice shapes accreted in clouds with MVD's of $120 \mu \mathrm{m}$ or less.
\end{abstract}

\section{Nomenclature}

$A_{c} \quad$ Accumulation parameter, dimensionless

$b \quad$ Relative heat factor, dimensionless

c $\quad$ Airfoil chord, $\mathrm{cm}$

$d \quad$ Cylinder diameter or twice the leading-edge radius of airfoil, $\mathrm{cm}$

$K \quad$ Splashing factor, defined in Introduction, dimensionless

$K_{0} \quad$ Modified inertia parameter, dimensionless

$L W C \quad$ Cloud liquid-water content, $\mathrm{g} / \mathrm{m}^{3}$

MVD Water droplet median volume diameter, $\mu \mathrm{m}$

$n \quad$ Freezing fraction, dimensionless

*Senior Research Associate, Member
Oh Ohnesorge number, defined in Introduction, dimensionless

Re Reynolds number of model, dimensionless

$R e_{\delta} \quad$ Reynolds number of water droplet, dimensionless

$t_{s t} \quad$ Static temperature, ${ }^{\circ} \mathrm{C}$

$t_{\text {tot }} \quad$ Total temperature, ${ }^{\circ} \mathrm{C}$

$V \quad$ Air velocity, $\mathrm{m} / \mathrm{s}$

We Weber number based on droplet size and water properties, dimensionless

$\beta_{0} \quad$ Collection efficiency at stagnation line, dimensionless

$\theta \quad$ Air energy transfer parameter, ${ }^{\circ} \mathrm{C}$

$\tau \quad$ Accretion time, min

$\phi \quad$ Droplet energy transfer parameter, ${ }^{\circ} \mathrm{C}$

$\underline{\text { Subscripts }}$

$R \quad$ Reference

$S \quad$ Scale

\section{$\underline{\text { Introduction }}$}

Proposed new icing certification rules to include testing with super-cooled large droplet (SLD) in addition to Appendix-C conditions are being considered for implementation within the next few years. When these new rules are established, test facilities will need to provide means for testing at or simulating SLD conditions. Existing Appendix-C calibrations will need to be expanded to include the new conditions. In addition, scaling techniques will be needed both to permit SLD-cloud testing of models smaller than full size and to simulate SLD droplet size effects with tests using Appendix-C MVDs. This report describes tests made in March 2001 in the IRT to provide a preliminary study of how effectively existing scaling methods can be applied to scale SLD drop sizes to Appendix-C conditions.

For some time it has been recognized that droplet splashing and breakup may influence ice accretion. ${ }^{1}$ Studies have identified parameters with which droplet splashing effects can be correlated. ${ }^{2,3}$ Reference 3 introduced the $K$ factor, $K=O h \operatorname{Re}_{\delta}^{1.25}$, where $O h$ $=W e^{1 / 2} / R e_{\delta}$ is the Ohnesorge number. In these relationships, both $W e$ and $R e_{\delta}$ are based on the droplet 
$M V D$ and water properties. The $K$ factor increases with velocity and $M V D$, and splashing only occurs when $K$ is greater than a threshold value. Typically, $K$ will be greater for SLD drop sizes than for those within Appendix C. Whether this $K$ factor or its splashing threshold applies in icing conditions is not known, but it is thought that splashing in SLD conditions could have a much greater effect on ice accretion than for Appendix-C clouds. If so, scaling for SLD conditions may require new approaches.

For scaling within Appendix C, the Ruff scaling method $^{4}$ has been shown to be effective. As used in atmospheric-pressure tunnels, this method maintains constant values of modified inertia parameter, $K_{0}$, accumulation parameter, $A_{c}$, and two energy-balance terms: the freezing fraction, $n$, and either the waterenergy transfer parameter, $\phi$, or the air-energytransfer parameter, $\theta$. The stagnation collection efficiency, $\beta_{0}$, is a function only of $K_{0}$, so that matching $K_{0}$ assures that $\beta_{0}$ for the scale and reference test will be the same. With $\beta_{0 S}=\beta_{0 R}$, matching $A_{c}$ assures that the quantity of ice accreted, relative to the chord, for the scale and reference test will be identical. The freezing fraction, $n$, is a heat-balance parameter with a strong effect on the shape of the ice, and $\phi$ and $\theta$ also have a small effect on ice shape. $n$, $\phi$, and $\theta$ come from the heat-balance analysis of Messinger. ${ }^{5}$ These requirements produce four equations that can be solved simultaneously to determine the scale droplet size, spray time, liquid-water content and temperature.

In the Ruff method, the user chooses the scale velocity. In addition to other approaches, the scale velocity can be determined by requiring that either $W e$ or $R e$ be matched between scale and reference conditions. Scaling studies in the IRT ${ }^{6,7}$ showed that scale tests produced the closest match to reference ice shapes when a scale velocity was used that was the average of that found from keeping $W e$ constant and that from keeping $R e$ constant between scale and reference cases.

The study of reference 1 showed that splashing depends in part on the thickness of the water film on the surface. Therefore, because the liquid water-film thickness must be dependent on the freezing fraction, different SLD effects may be evident for different freezing fractions. The present study was performed with freezing fractions of $0.3,0.6$ and 1.0. Rime tests were included because they provide a good check on tunnel calibrations. If the tunnel calibration is consistent, the correct scale rime accre- tion is always obtained as long as the modified inertia parameter, $K_{0}$, and accumulation parameter, $A_{c}$, are matched between scale and reference.

There have been no previous experimental studies of scaling for SLD conditions. However, a preliminary analysis $^{8}$ of scaling from $200 \mu \mathrm{m}$ to Appendix-C drop sizes of 40 or $50 \mu \mathrm{m}$ concluded that to satisfy $K_{0 S}=K_{0 R}$, as the Ruff method requires, scale model size would need to be $1 / 5^{\text {th }}$ the reference or smaller. Scaling for models smaller than $1 / 3^{\text {rd }}$ the reference have not been successfully demonstrated, so there would be little confidence in the results of scaling to $1 / 5^{\text {th }}$ size. Consequently, the study concluded that there were presently no validated ways to simulate SLD tests by using Appendix-C droplet sizes. However, a later study ${ }^{9}$ demonstrated that the requirement of equating scale and reference values of $K_{0}$ could be relaxed providing the stagnation collection efficiency, $\beta_{0}$, matched within about $10 \%$. For the present study, this relaxed standard was used, and scale models from $1 / 1.7^{\text {th }}$ to $1 / 1$ of the reference size were used.

The reference conditions for this series of tests used four of the five specific $M V D-L W C$ combinations for which the IRT has been calibrated in the SLD regime. ${ }^{10}$ The calibration was made for 3 airspeeds: 100,150 and $200 \mathrm{kt}$. For the tests reported here, only the 100 - and 150 -kt reference airspeeds were used. Table I shows the conditions chosen for each reference case. The cases were assigned a 3-digit number followed by 'SLD'. The first digit relates to the reference airspeed, with 1 indicating $100 \mathrm{kt}$ and 2, $150 \mathrm{kt}$. The second digit refers to the reference $M V D$, with 2 representing $175 \mu \mathrm{m}, 3,120 \mu \mathrm{m}$, $4,100 \mu \mathrm{m}$ and $5,70 \mu \mathrm{m}$. The third digit in the case designation pertains to the freezing fraction, with 0 used for $n=1.0,2$ for $n=0.6$ and 5 for $n=0.3$. The reference model for all tests was a 91.4-cm-chord NACA 0012 full-span wing section.

\section{Test Description}

The tests were performed in the NASA Glenn Icing Research Tunnel (IRT) in March 2001. The IRT is a closed-loop refrigerated icing tunnel. In the summer of 2000 a complete cloud calibration ${ }^{10}$ was completed following the installation of a new heat exchanger and other upgrades. ${ }^{11}$ The tunnel loop is shown in figure 1(a). As part of the modifications, new $\mathrm{C}$ - and D- corner turning vanes were installed and the tunnel was extended to the west by $6 \mathrm{~m}$ to provide room for the new heat exchanger. This extension on the tunnel shell created more distance 
Table I. Reference Conditions for SLD Scaling

Reference Model: 91.4-cm-Chord NACA 0012

\begin{tabular}{|c|c|c|c|c|c|c|c|c|c|c|}
\hline Case & $\begin{array}{c}t_{s t}, \\
{ }^{\circ} \mathrm{C}\end{array}$ & $\begin{array}{c}t_{\text {tot, }}, \\
{ }^{\circ} \mathrm{C}\end{array}$ & $\begin{array}{c}V, \\
\mathrm{kt}\end{array}$ & $\begin{array}{c}V, \\
\mathrm{~m} / \mathrm{s}\end{array}$ & $\begin{array}{c}M V D, \\
\mu \mathrm{m}\end{array}$ & $\begin{array}{c}L W C, \\
\mathrm{~g} / \mathrm{m}^{3}\end{array}$ & $\begin{array}{c}\tau, \\
\mathrm{min}\end{array}$ & $\begin{array}{c}\beta_{0} \\
\%\end{array}$ & $A_{c}$ & $n$ \\
\hline 130SLD & -29 & -28 & 100 & 51.5 & 120 & 1.01 & 16.1 & 94 & 1.90 & 1.00 \\
\hline 122SLD & -23 & -22 & 100 & 51.5 & 175 & 1.68 & 9.7 & 96 & 1.90 & 0.60 \\
\hline 132SLD & -17 & -15 & 100 & 51.5 & 120 & 1.01 & 16.1 & 94 & 1.90 & 0.60 \\
\hline 230SLD & -27 & -24 & 150 & 77.2 & 120 & 0.69 & 15.8 & 95 & 1.90 & 1.00 \\
\hline 250SLD & -23 & -20 & 150 & 77.2 & 70 & 0.60 & 18.1 & 90 & 1.90 & 1.00 \\
\hline 222SLD & -20 & -17 & 150 & 77.2 & 175 & 0.99 & 11.0 & 96 & 1.90 & 0.60 \\
\hline 232SLD & -16 & -13 & 150 & 77.2 & 120 & 0.69 & 15.8 & 94 & 1.90 & 0.60 \\
\hline 242SLD & -16 & -13 & 150 & 77.2 & 100 & 0.68 & 16.0 & 93 & 1.90 & 0.60 \\
\hline 252SLD & -14 & -11 & 150 & 77.2 & 70 & 0.60 & 18.1 & 90 & 1.90 & 0.60 \\
\hline 225SLD & -10 & -7 & 150 & 77.2 & 175 & 0.99 & 11.0 & 96 & 1.90 & 0.30 \\
\hline 235SLD & -8 & -5 & 150 & 77.2 & 120 & 0.69 & 15.8 & 94 & 1.90 & 0.30 \\
\hline 245SLD & -8 & -5 & 150 & 77.2 & 100 & 0.68 & 16.0 & 93 & 1.90 & 0.30 \\
\hline
\end{tabular}

from the turning vanes to the spray bars on the south side of the settling chamber. The IRT has 10 spray bars, an arrangement in use since 1998.

The IRT spray-bar system uses two separate water manifolds. The water pressure of each can be controlled independently. This set-up allows both Standard and Mod-1 nozzle sets to be installed at all times so that it's possible to switch rapidly and easily between nozzle sets as test conditions require. All results presented here were obtained with Mod-1 nozzles.

The models used for these tests were all NACA 0012 wing sections. They included a full-span $(183-\mathrm{cm})$ 91.4-cm-chord fiberglass model pictured in figure 1(b) and 61-cm-span aluminum airfoil sec-

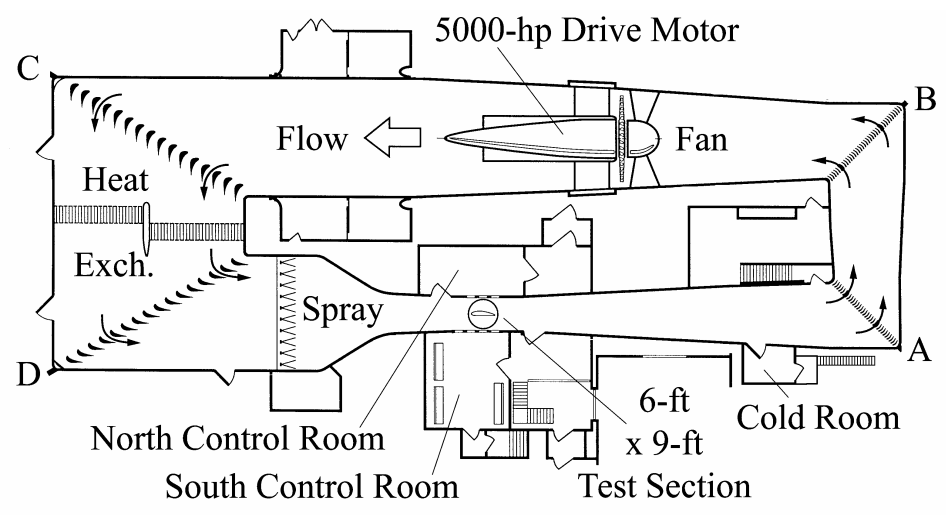

(a) NASA Glenn Icing Research Tunnel. Revised Loop with New Heat Exchanger Installed in 2000.

Figure 1. Facility and Model Description. tions with 80.0 - and $53.3-\mathrm{cm}$ chord. The $61-\mathrm{cm}-$ span models were mounted between splitter plates as shown typically in figure 1(c). At the bottom, the splitter plates were supported on a stand mounted to the tunnel turntable. The upper splitter plates were secured to a frame attached to a hollow cylinder at the ceiling of the tunnel. This cylinder fit closely around a vertical pipe section attached to the tunnel ceiling. This arrangement permitted rotation of the model for angle of attack changes, but all tests were run at $0^{\circ} \mathrm{AOA}$. All models were tested in a vertical orientation in the center of the test section. Because of the rapid-start capability of the current IRT spray system, the models were not shielded during the initiation of the spray.

In preparing for a test, the temperature and airspeed in the test section and the air and water pressures on the spray manifolds were set. When these conditions had stabilized the spray nozzle valves were opened to initiate the spray. The spray was timed for the required duration, then turned off. The fan was brought to a full stop and the tunnel entered to record the ice shape. A thin heated plate with a cut-out of the model shape was inserted into the leading edge of the ice to melt a thin horizontal slice down to the clean model surface. A cardboard template was placed into this gap and an outline of the ice accretion traced. Tracings were taken at the vertical center of the tunnel $(91 \mathrm{~cm}$ from the floor) and at $2.5 \mathrm{~cm}$ above the center. These 


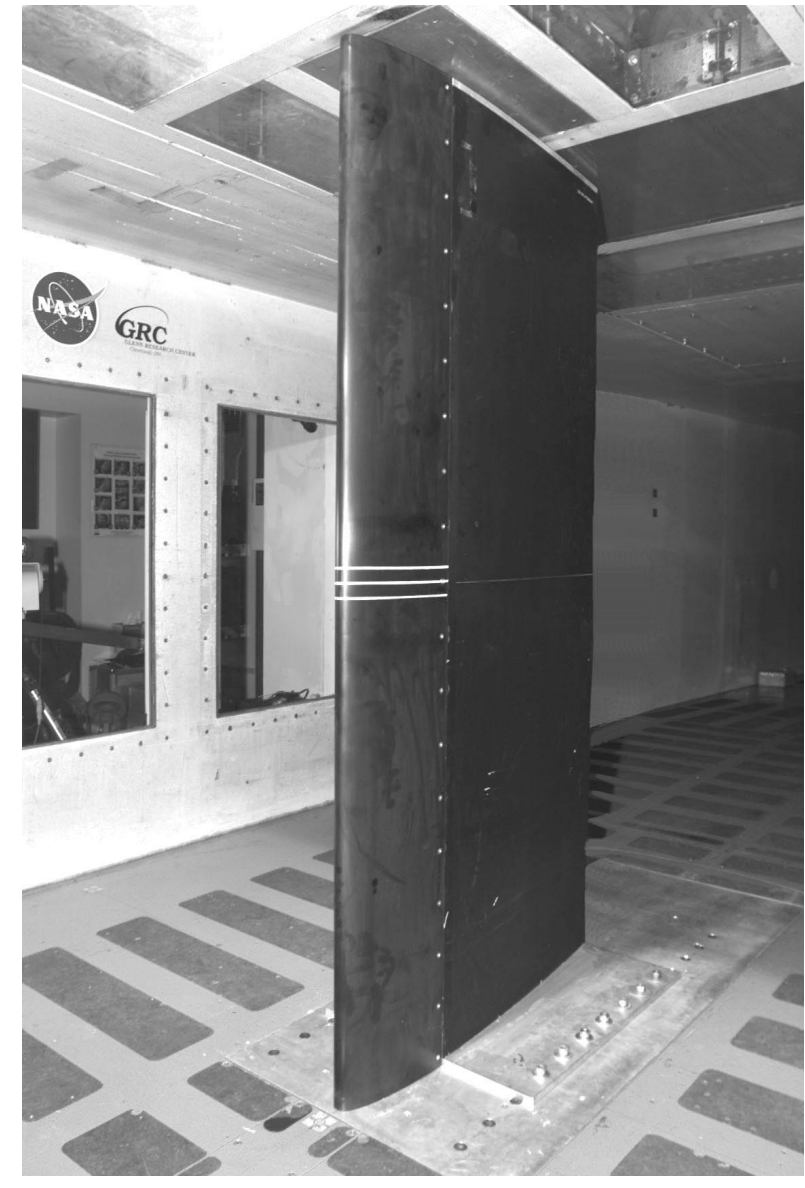

(b) 91.4-cm-Chord NACA 0012 Model in IRT Test Section.

Figure 1. (con't)

tracings were digitized and the $x-y$ coordinates for each ice shape were recorded. The coordinates were normalized with respect to the model chord and plotted for comparison of ice shapes. In this paper, only centerline shapes will be presented.

\section{Test Condition and Similarity Parameter Uncertainties}

Tunnel and cloud conditions were recorded at 3-sec intervals over the duration of each test. Reported conditions are the time averages of these records. Estimates of the uncertainty in the reported average conditions were made by considering fluctuations of the values with time, possible instrument errors including calibration, uncertainties in tunnel calibration of $M V D$ and $L W C$ and observed differences in measurements from one location to another in the test section.

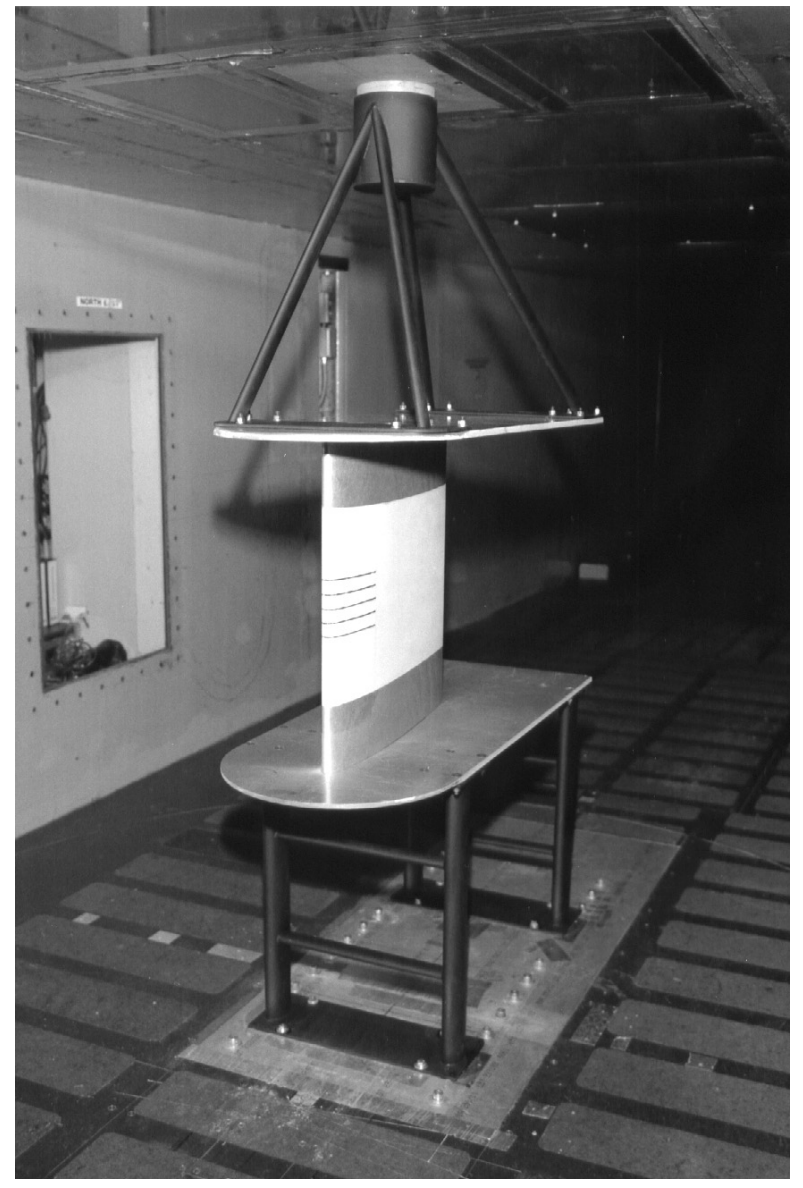

(c) 80.0-cm-Chord NACA 0012 Model in IRT Test Section. 53.3-cm-Chord Model Similar.

Figure 1. (concluded).

Total temperature was estimated to have an uncertainty of about $\pm 0.5^{\circ} \mathrm{C}$, velocity, $\pm 1 \mathrm{~m} / \mathrm{s}$, liquid-water content, $\pm 10 \%$ and median volume droplet diameter, $\pm 12 \%$.

Using the methods of Coleman and Steele, ${ }^{12}$ these estimated test-condition uncertainties led to an uncertainty of $17 \%$ in $K_{0}, 2 \%$ in $\beta_{0}, 12 \%$ in $A_{c}, 15 \%$ in $n, 1{ }^{\circ} \mathrm{C}$ each in $\phi$ and $\theta, 2 \%$ in $R e$ and $12 \%$ in $W e$.

\section{Scaling Approach}

An objective of the SLD scaling tests described here was to determine if Appendix-C conditions could be used to simulate SLD conditions by applying established scaling methods. Because the Ruff scaling method $^{4}$ for tunnels without pressure control has proven effective, it was chosen as the basis for the scaling applied. As noted in the Introduction, for scaling of either model size or test conditions, the 
Ruff method requires that the similarity parameters $K_{0}, A_{c}, n$ and either $\phi$ or $\theta$ have the same respective values for both scale and reference conditions.

For this study, an $M V D$ of $50 \mu \mathrm{m}$, the largest droplet size within the Appendix-C envelope, was chosen for all scale tests. Scale models were NACA 0012 airfoil sections of 91-, 80- and 53-cm chord. The scale temperature and $L W C$ were found by matching $\phi$ and $n$ to their respective reference values, and the scale velocity was determined using either the constant-We or average- $V$ methods. With both model size and $M V D$ selected for each scale test, the parameter $K_{0}$ (and therefore $\beta_{0}$ ) could not be matched. For all tests, however, the scale and reference $\beta_{0}$ 's were found to differ by less than $10 \%$. The normal practice with the Ruff method is to find scale icing time by simply equating scale and reference $A_{c}$. This insures the same relative quantity of ice accretion. However, because the scale and reference $\beta_{0}$ were not the same for these tests, the scale time was found by matching the product $A_{c} \beta_{0}$. The reference value chosen for $A_{c}$ was the same as that of previous IRT scaling tests to facilitate comparisons with earlier results.

\section{$\underline{\text { Results }}$}

Table II shows the matrix of scale tests performed. Only a representative sample of centerline shapes will be given here. There was no significant difference between the centerline shapes and those recorded $2.5 \mathrm{~cm}$ above center.

\section{IRT Calibration Consistency}

Rime tests made over a range of conditions while maintaining constant $A_{c}$ and $K_{0}$ should produce identical ice shapes. Of particular interest for the present series of tests is whether the $L W C$ calibration performed for SLD conditions is consistent with that of Appendix C. In figure 2, a $120-\mu \mathrm{m}$ SLD shape is compared with a $70-\mu \mathrm{m}$ SLD shape (fig. 2(a)) and with a 40- $\mu \mathrm{m}$ Appendix-C shape (fig. 2(b)). The $120-\mu \mathrm{m} M V D$ shape for this figure is shown shaded, while the 70- and 40- $\mu \mathrm{m}$ shapes are each represented by a solid line. Below the figure are the average test conditions recorded during each test run and some of the corresponding similarity parameters of interest. Because the recorded conditions may have differed slightly from the planned set conditions for each

Table II. Matrix of SLD Scaling Tests

IRT, March 2001

\begin{tabular}{|c|c|c|c|c|c|c|c|c|c|c|}
\hline \multirow{2}{*}{ Case } & \multirow{2}{*}{$n$} & \multicolumn{3}{|c|}{$\begin{array}{c}\text { Reference } \\
c=91.4 \mathrm{~cm}\end{array}$} & \multicolumn{3}{c|}{$\begin{array}{c}\text { Average- } V \text { Scale } \\
M V D=50 \mu \mathrm{m}\end{array}$} & \multicolumn{3}{c|}{$\begin{array}{c}\text { Constant-We Scale } \\
M V D=50 \mu \mathrm{m}\end{array}$} \\
\cline { 2 - 13 } & & $\begin{array}{c}V, \\
\mathrm{kt}\end{array}$ & $\begin{array}{c}V, \\
\mathrm{~m} / \mathrm{s}\end{array}$ & $\begin{array}{c}M V D, \\
\mu \mathrm{m}\end{array}$ & $\begin{array}{c}c, \\
91.4 \mathrm{~cm}\end{array}$ & $\begin{array}{c}c, \\
80.0 \mathrm{~cm}\end{array}$ & $\begin{array}{c}c, \\
53.3 \mathrm{~cm}\end{array}$ & $\begin{array}{c}c, \\
91.4 \mathrm{~cm}\end{array}$ & $\begin{array}{c}c, \\
80.0 \mathrm{~cm}\end{array}$ & $\begin{array}{c}c, \\
53.3 \mathrm{~cm}\end{array}$ \\
\hline 130SLD & 1.0 & 100 & 51.5 & 120 & & & & & $\mathrm{x}$ & $\mathrm{x}$ \\
\hline 122SLD & 0.6 & 100 & 51.5 & 175 & $\mathrm{x}$ & $\mathrm{x}$ & $\mathrm{x}$ & $\mathrm{x}$ & & \\
\hline 132SLD & 0.6 & 100 & 51.5 & 120 & $\mathrm{x}$ & $\mathrm{x}$ & & & $\mathrm{x}$ & \\
\hline 230SLD & 1.0 & 150 & 77.2 & 120 & $\mathrm{x}$ & $\mathrm{x}$ & & $\mathrm{x}$ & $\mathrm{x}$ & \\
\hline 250SLD & 1.0 & 150 & 77.2 & 70 & & & $\mathrm{x}$ & & & $\mathrm{x}$ \\
\hline 222SLD & 0.6 & 150 & 77.2 & 175 & $\mathrm{x}$ & $\mathrm{x}$ & $\mathrm{x}$ & $\mathrm{x}$ & $\mathrm{x}$ & $\mathrm{x}$ \\
\hline 232SLD & 0.6 & 150 & 77.2 & 120 & $\mathrm{x}$ & $\mathrm{x}$ & $\mathrm{x}$ & $\mathrm{x}$ & $\mathrm{x}$ & $\mathrm{x}$ \\
\hline 242SLD & 0.6 & 150 & 77.2 & 100 & $\mathrm{x}$ & $\mathrm{x}$ & $\mathrm{x}$ & $\mathrm{x}$ & $\mathrm{x}$ & $\mathrm{x}$ \\
\hline 252SLD & 0.6 & 150 & 77.2 & 70 & $\mathrm{x}$ & & $\mathrm{x}$ & $\mathrm{x}$ & & $\mathrm{x}$ \\
\hline 225SLD & 0.3 & 150 & 77.2 & 175 & $\mathrm{x}$ & $\mathrm{x}$ & $\mathrm{x}$ & & & $\mathrm{x}$ \\
\hline 235SLD & 0.3 & 150 & 77.2 & 120 & $\mathrm{x}$ & $\mathrm{x}$ & & & & $\mathrm{x}$ \\
\hline 245SLD & 0.3 & 150 & 77.2 & 100 & $\mathrm{x}$ & $\mathrm{x}$ & & & & $\mathrm{x}$ \\
\hline
\end{tabular}

$\mathrm{x}$ indicates completed scale test 

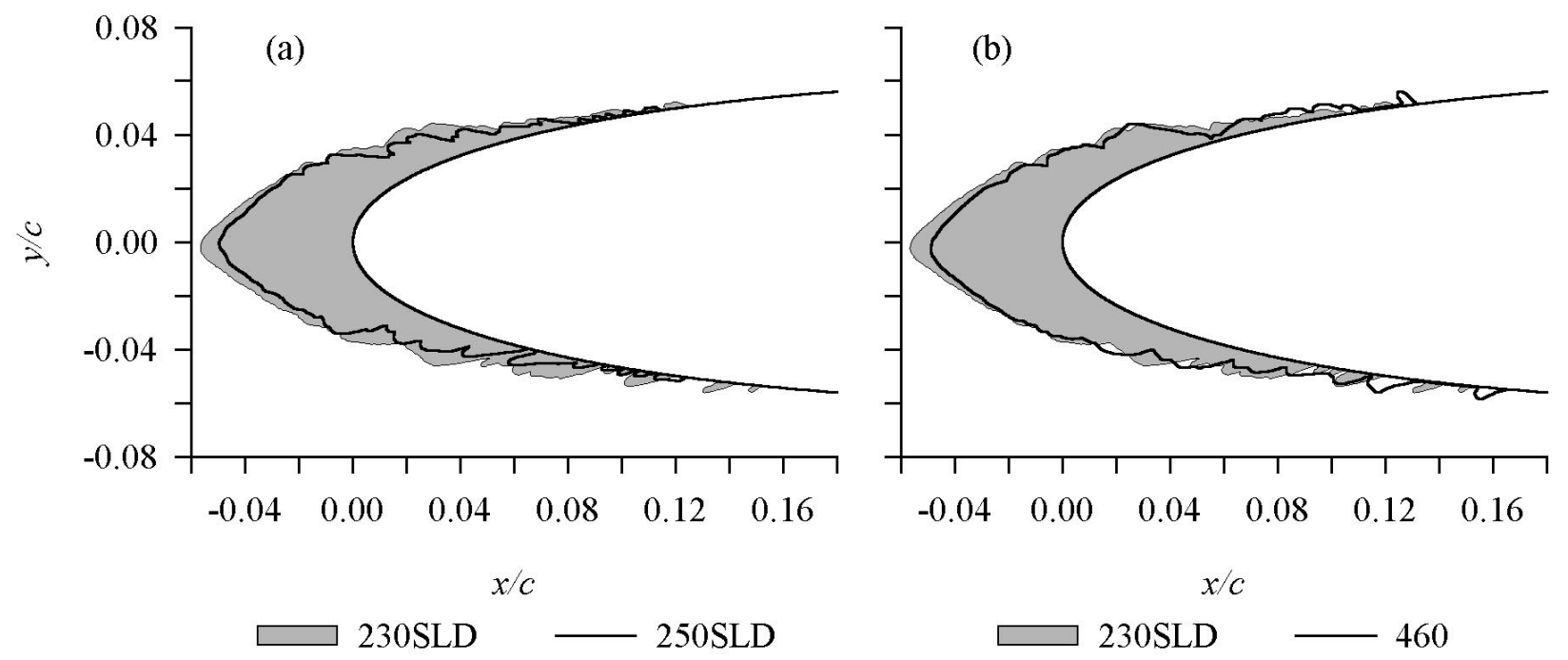

(a) Scaling from 120 to $70 \mu \mathrm{m} M V D$. Scale chord, $91.4 \mathrm{~cm}$.

(b) Scaling from 120 to $40 \mu \mathrm{m} M V D$. Scale chord, $53.3 \mathrm{~cm}$.

\begin{tabular}{lrrrrrrrrrrrrrrrrr}
\multicolumn{1}{c}{ Case } & Date/Run & $\begin{array}{c}c, \\
\mathrm{~cm}\end{array}$ & $\begin{array}{c}t_{s t}, \\
{ }^{\circ} \mathrm{C}\end{array}$ & $\begin{array}{c}V, \\
\mathrm{~m} / \mathrm{s}\end{array}$ & $\begin{array}{c}M V D, \\
\mu \mathrm{m}\end{array}$ & $\begin{array}{c}L W C, \\
\mathrm{~g} / \mathrm{m}^{3}\end{array}$ & $\begin{array}{c}\tau, \\
\mathrm{min}\end{array}$ & $K_{0}$ & $\beta_{0}$ & $A_{c}$ & $n$ & $b$ & $\begin{array}{c}\phi, \\
{ }^{\circ} \mathrm{C}\end{array}$ & $\begin{array}{c}\theta, \\
{ }^{\circ} \mathrm{C}\end{array}$ & $\begin{array}{c}R e, \\
10^{4}\end{array}$ & $\begin{array}{l}W e, \\
10^{3}\end{array}$ \\
230SLD & $3-12-01 / 6$ & 91.4 & -27.0 & 77.3 & 120 & 0.69 & 15.8 & 20.3 & 0.95 & 1.91 & 1.00 & 1.00 & 26.3 & 33.5 & 18.7 & 11.0 \\
(a) 250SLD & $3-9-01 / 7$ & 91.4 & -23.4 & 77.3 & 70 & 0.60 & 18.1 & 8.9 & 0.90 & 1.90 & 1.00 & 0.52 & 22.7 & 29.3 & 18.5 & 6.4 \\
(b) 460 & $3-21-01 / 4$ & 53.3 & -26.1 & 66.8 & 40 & 1.00 & 7.3 & 5.8 & 0.86 & 1.89 & 1.00 & 0.59 & 25.5 & 33.0 & 9.6 & 2.7
\end{tabular}

Figure 2. IRT Calibration Consistency. Reference Tests for Three Rime Cases.

test, the similarity parameters intended to be maintained may not always have matched precisely.

The leading-edge thicknesses were slightly different, but otherwise the shapes were the same. Even the $120-\mu \mathrm{m}$ feather size and location was simulated by the tests at the smaller drop sizes. The differences in leading-edge thickness were well within the uncertainty in $L W C$; therefore, these results provide confidence that the IRT calibration was consistent for SLD and Appendix-C conditions.

Note also from figure 2 that although the stagnation collection efficiencies, $\beta_{0}$, for each pair of tests did not match, they were close enough to produce good agreement of non-dimensional shapes and quantity of ice accreted. These results are consistent with the guideline ${ }^{9}$ that scale and reference $\beta_{0}$ values need only be within $10 \%$ for good match of ice shapes.

It is also worth noting that the ice shapes appeared to be independent of model span. The 91.4-cm-chord model was full span $(1.8 \mathrm{~m})$, while the $53.3-\mathrm{cm}$ chord model was partial span $(0.6 \mathrm{~m})$. This result indicates that flow around the ends of the partial- span model did not seem to have affected the cloud at the center of the model.

\section{Scaling from $70 \mu \mathrm{m}$ to $50 \mu \mathrm{m}$}

It was anticipated that scaling from 70 to $50 \mu \mathrm{m}$ would be accomplished easily since this situation represents little change in $M V D$. Consequently, only two cases with a $70-\mu \mathrm{m}$ reference $M V D$ were included in the test matrix. Table II shows that for case 250SLD $(n=1)$ two scale tests at MVD = $50 \mu \mathrm{m}$ were performed for comparison with the reference, and for case 252SLD $(n=0.6)$ four scale tests were made.

For the case 250SLD scale tests anomalous ice shapes were obtained. These shapes were unusually smooth and appeared to be eroded. The cause is still under investigation, but these results were felt to be unreliable and the ice shapes will not be shown.

As expected, for case 252SLD excellent agreement was obtained between the scale and reference ice shapes for both methods of finding scale velocity and each scale model size. Because successful scal- 
ing from larger $M V D$ s will be presented below, the results of scaling from $70 \mu \mathrm{m}$ will not be shown.

\section{Scaling from $100 \mu \mathrm{m}$ to $50 \mu \mathrm{m}$}

Two $100-\mu \mathrm{m}$ reference cases were included in the test matrix. Case 242SLD had a freezing fraction of 0.6 and case 245SLD had a freezing fraction of 0.3.

Six scale tests were performed for case 242SLD: each of the three scale models was tested using both average-velocity and constant-We methods to determine scale velocity. Figure 3(a) shows the scaling results using the average- $V$ method with a scale chord of $53 \mathrm{~cm}$. Figure $3(\mathrm{~b})$ gives the results for the constant-We method with the same scale model. The reference shape in this and subsequent figures is shown shaded while the scale shapes are each indicated by a solid line. Non-dimensional scale ice accretions matched the reference in quantity of ice, in shape and location of horns and in size and approximate locations of feather formations. Even the large feather structures just aft of the main ice horns were simulated reasonably well by the scale tests. There was no significant difference in results whether the average-velocity method or constant-We method was used to choose scale velocity.

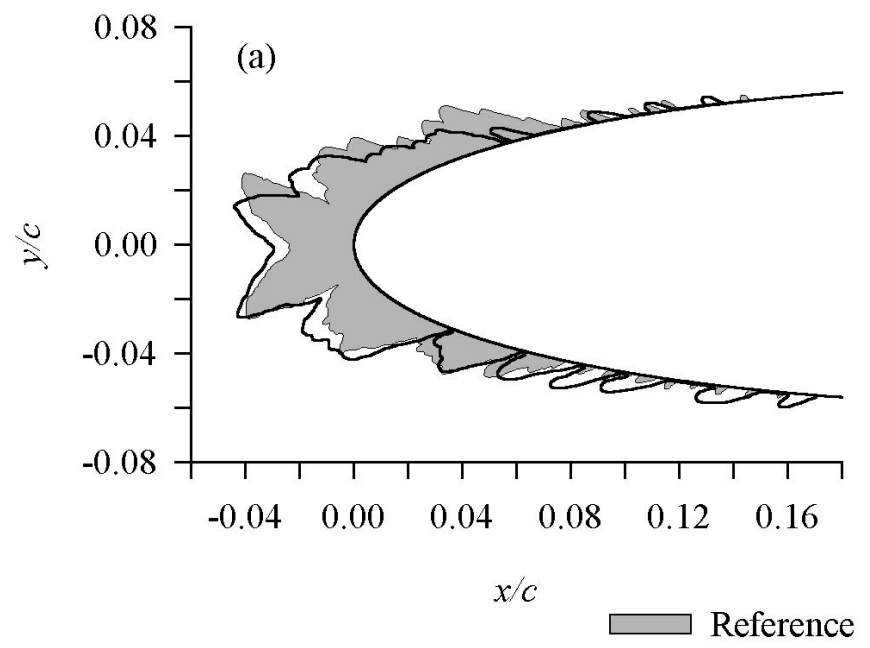

The ice shapes at a freezing fraction of 0.3 (Case 245SLD) differed in appearance from those obtained at 0.6 , but the scale tests using either scaling method matched the reference in non-dimensional size and shape. These results will not be shown.

Scaling from $120 \mu \mathrm{m}$ to $50 \mu \mathrm{m}$

Five cases had a reference $M V D$ of $120 \mu \mathrm{m}$. Two of these had a reference $V$ of $100 \mathrm{kt}$ (130SLD, with $n=$ 1.0 and 132SLD, with $n=0.6$ ) and three with a reference $V$ of $150 \mathrm{kt}$ (230SLD, with $n=1.0,232 \mathrm{SLD}$, with $n=0.6$ and 235SLD, with $n=0.3$ ). The scale tests for the rime cases, 130SLD and 230SLD, produced ice shapes that looked eroded, similar to those mentioned above for the 70 - to $50-\mu \mathrm{m}$ scaling tests, and these will not be discussed further.

Three scaling tests were performed for case 132SLD. Two of these used the average- $V$ method (scale model chords of 91.4 and $80 \mathrm{~cm}$ ) and one, the constant-We (80.0-cm scale model chord). Within typical repeatability of ice shapes, all scale tests simulated the reference accretion in terms of the non-dimensional size, horn location, horn angle and feather size and density. There was a tendency for the non-dimensional scale horns to be slightly larger

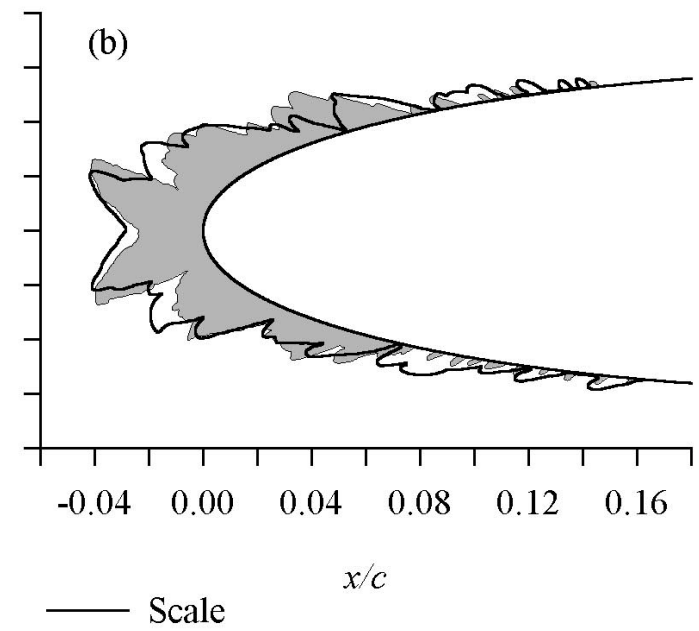

(b) Constant-We method. Scale chord, $53.3 \mathrm{~cm}$.

(a) Average- $V$ method. Scale chord, $53.3 \mathrm{~cm}$.

\begin{tabular}{|c|c|c|c|c|c|c|c|c|c|c|c|c|c|c|c|c|}
\hline Method & Date/Run & $\begin{array}{l}c, \\
\mathrm{~cm}\end{array}$ & $\begin{array}{l}t_{s t}, \\
{ }^{\circ} \mathrm{C}\end{array}$ & $\begin{array}{c}V, \\
\mathrm{~m} / \mathrm{s}\end{array}$ & $\begin{array}{c}M V D \\
\mu \mathrm{m}\end{array}$ & $\begin{array}{c}L W C, \\
\mathrm{~g} / \mathrm{m}^{3}\end{array}$ & $\underset{\min }{\tau,}$ & $K_{0}$ & $\beta_{0}$ & $A_{c}$ & $n$ & $b$ & $\begin{array}{l}\phi, \\
{ }^{\circ} \mathrm{C}\end{array}$ & $\begin{array}{l}\theta, \\
{ }^{\circ} \mathrm{C}\end{array}$ & $\begin{array}{l}\text { Re, } \\
10^{4}\end{array}$ & $\begin{array}{l}W e, \\
10^{3}\end{array}$ \\
\hline Reference & $3-9-01 / 1$ & 91.4 & -15.7 & 77.5 & 100 & 0.68 & 16.0 & 15.3 & 0.93 & 1.91 & 0.60 & 0.61 & 15.0 & 20.0 & 17.6 & 9.2 \\
\hline (a) Avg- $V$ & $3-19-01 / 9$ & 53.3 & -16.8 & 126.2 & 50 & 0.56 & 7.0 & 12.1 & 0.92 & 1.92 & 0.60 & 0.50 & 14.9 & 16.4 & 16.0 & 12.3 \\
\hline b) $\mathrm{C}-\mathrm{We}$ & $3-20-01 / 4$ & 53.3 & -16.3 & 109.2 & 50 & 0.67 & 6.8 & 11.1 & 0.91 & 1.92 & 0.60 & 0.55 & 14.9 & 17.8 & 14.0 & 9.2 \\
\hline
\end{tabular}

Figure 3. Scaling from 100 to $50 \mu \mathrm{m} M V D$ with freezing fraction of 0.6 . Case 242SLD. Reference chord, $91.4 \mathrm{~cm}$. 
than the reference, but this difference was not judged significant. Scale results were independent of both scale model size and method of determining scale velocity.

Scale tests for case 232SLD, with a freezing fraction of 0.6 , included both methods of finding scale velocity applied to all three model sizes. All of these scaling tests produced at least fair agreement with the reference shape. Two examples are shown in figure 4 , which compares the $53-\mathrm{cm}$ scale model results with reference shapes.

The average- $V$ scaling for this case, shown in figure 4(a), gave the poorest match of non-dimensional shape and quantity of the three model sizes tested with this method, while the constant-We results in 4(b) illustrate the best of the three model sizes. For this latter test, the reference ice shape horns were simulated well by the scale result, as were the sizes and approximate spacing of feather structures aft of the main shape. It was concluded that differences between the methods were only random in nature, since each gave excellent scaling results at one of the model sizes. Additional tests of this case are needed, however, to confirm this conclusion.
Case 235SLD had a freezing fraction of 0.3. Two scaling tests were made with the average- $V$ method, and results of these are given in figure 5. Figure 5(a) shows scale ice shapes for a scale model of 91.4-cm chord, and 5(b) for a scale model of $80.0-\mathrm{cm}$ chord. Both scale tests produced an excellent simulation of the reference ice shape, including the horn size, location and angle and feather sizes and spacing. The constant-We method with a model chord of $53.3 \mathrm{~cm}$ was also tested with similarly excellent results. This shape is not illustrated.

\section{Scaling from $175 \mu \mathrm{m}$ to $50 \mu \mathrm{m}$}

Three $175-\mu \mathrm{m}$-reference cases were included in the study. The non-dimensional scale ice shapes for cases 122SLD and 222SLD were markedly smaller than the reference shapes and for some tests appeared to be eroded. Additional study is required to understand these results.

Case 225 SLD had a 150 -kt reference velocity and a freezing fraction of 0.3 . Average- $V$ scaling was applied for each of the three model sizes, and constant$W e$ was used for the $53.3-\mathrm{cm}$ model. Figure 6 shows typical scaling results. Figure 6(a) shows results for

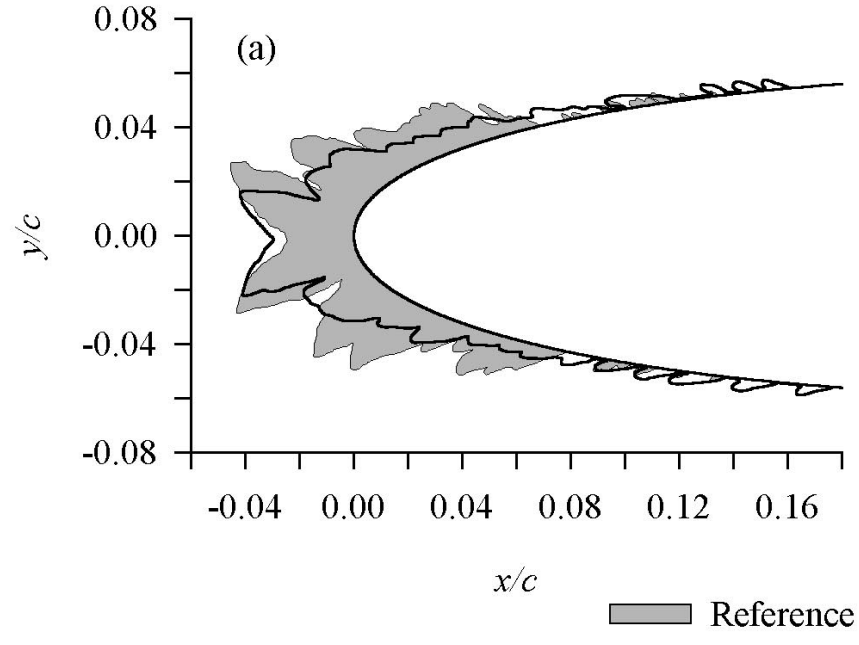

(a) Average- $V$ method. Scale chord, $53.3 \mathrm{~cm}$.

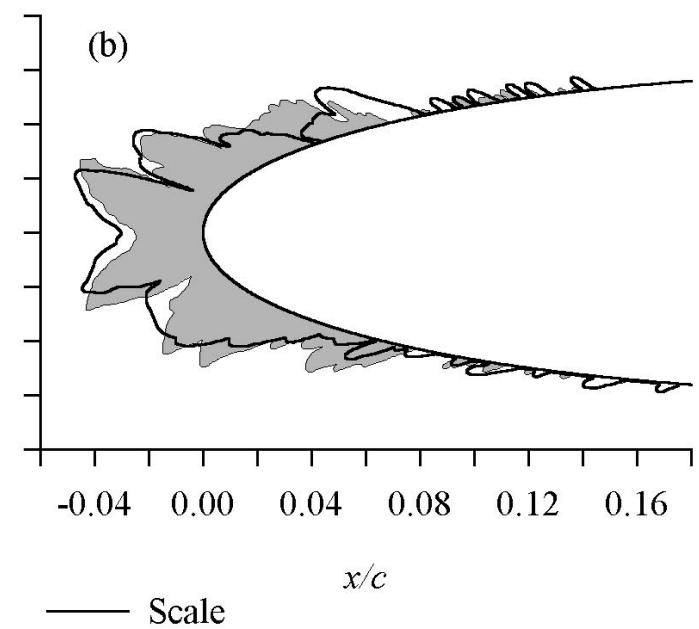

(b) Constant-We method. Scale chord, $53.3 \mathrm{~cm}$.
Method Date/Run $\quad c, \quad t_{s t}, \quad V, \quad M V D, L W C, \quad \tau$
$\begin{array}{llllllllll}\tau, & K_{0} & \beta_{0} & A_{c} & n & b & \begin{array}{c}\phi, \\ { }^{\circ} \mathrm{C}\end{array} & \begin{array}{c}\theta, \\ { }^{\circ} \mathrm{C}\end{array} & 10^{4} & 10^{3}\end{array}$
$\begin{array}{lllllllllllllllll}\text { Reference } & 3-9-01 / 2 & 91.4 & -16.0 & 77.5 & 120 & 0.69 & 15.8 & 20.2 & 0.95 & 1.91 & 0.60 & 0.64 & 15.3 & 20.5 & 17.7 & 11.1\end{array}$

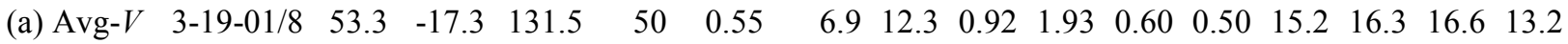

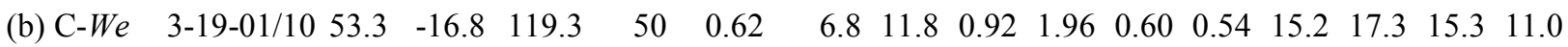

Figure 4. Scaling from 120 to $50 \mu \mathrm{m} M V D$ with freezing fraction of 0.6 . Case 232SLD. Reference chord, $91.4 \mathrm{~cm}$. 


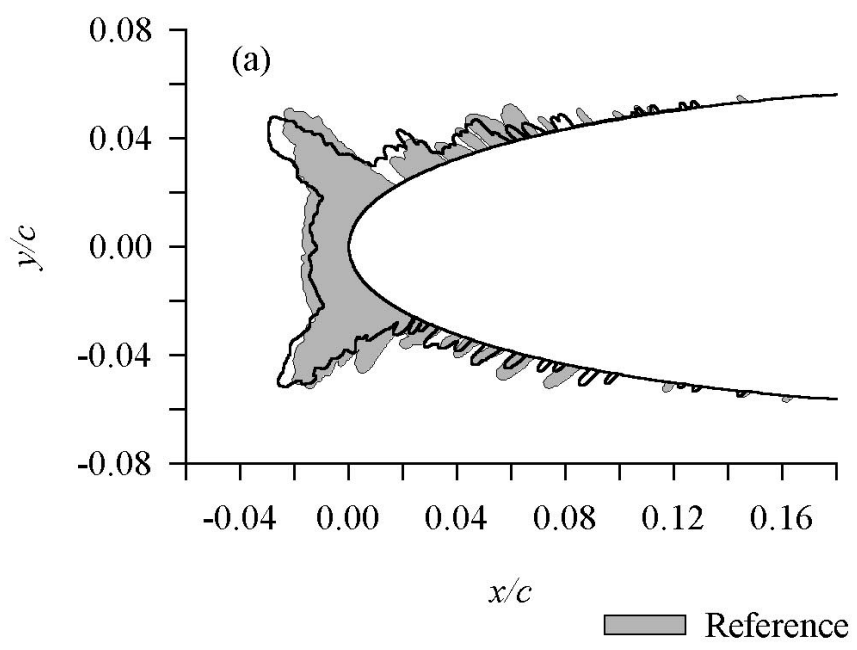

(a) Scale chord, $91.4 \mathrm{~cm}$.

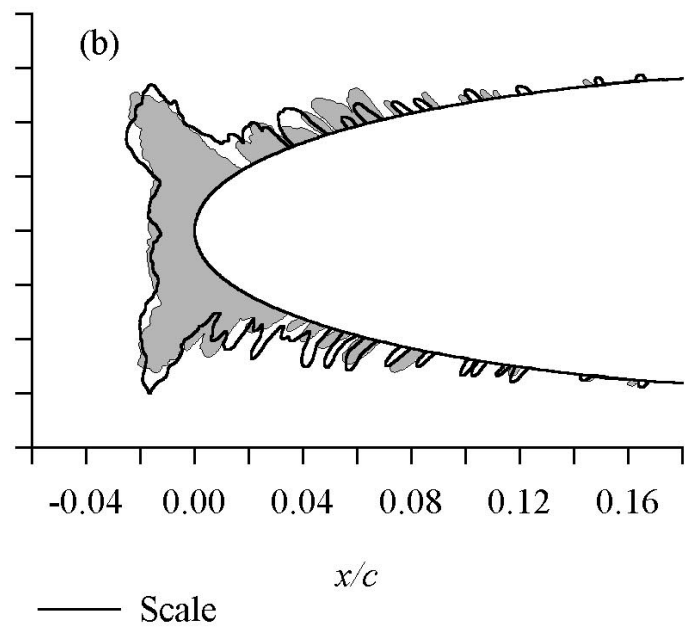

(b) Scale chord, $80.0 \mathrm{~cm}$.

\begin{abstract}
$\begin{array}{cccccccccccccccc}\text { Method Date/Run } & c, & t_{s t}, & V, & M V D, & L W C, & \tau, & K_{0} & \beta_{0} & A_{c} & n & b & \phi, & \theta, & R e, & W e \text {, } \\ & \mathrm{cm} & { }^{\circ} \mathrm{C} & \mathrm{m} / \mathrm{s} & \mu \mathrm{m} & \mathrm{g} / \mathrm{m}^{3} & \min & & & & & & & \end{array}$
$\begin{array}{lllllllllllllllll}\text { Reference } & 3-7-01 / 4 & 91.4 & -8.4 & 77.0 & 120 & 0.69 & 15.8 & 20.2 & 0.95 & 1.90 & 0.30 & 0.63 & 7.7 & 10.2 & 16.7 & 10.9\end{array}$

$\begin{array}{lllllllllllllllll}\text { (a) Avg- } V & 3-7-01 / 1 & 91.4 & -8.9 & 98.7 & 50 & 0.58 & 14.7 & 6.2 & 0.86 & 1.90 & 0.30 & 0.56 & 7.7 & 8.9 & 21.0 & 7.5\end{array}$

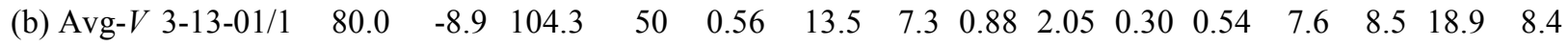

Figure 5. Scaling from 120 to $50 \mu \mathrm{m} M V D$ with freezing fraction of 0.3. Case 235SLD. Reference chord, $91.4 \mathrm{~cm}$.

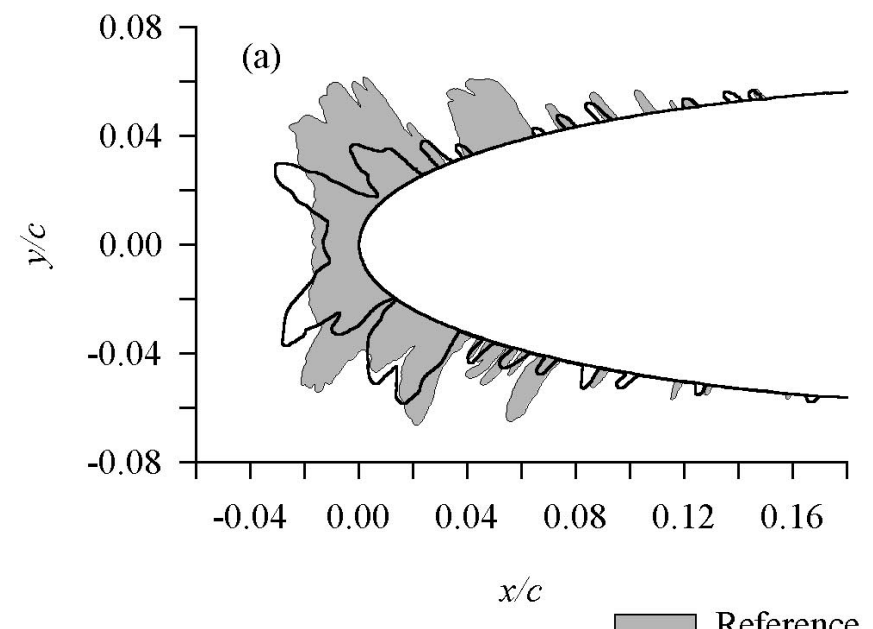

(a) Average- $V$ method. Scale chord, $53.3 \mathrm{~cm}$.

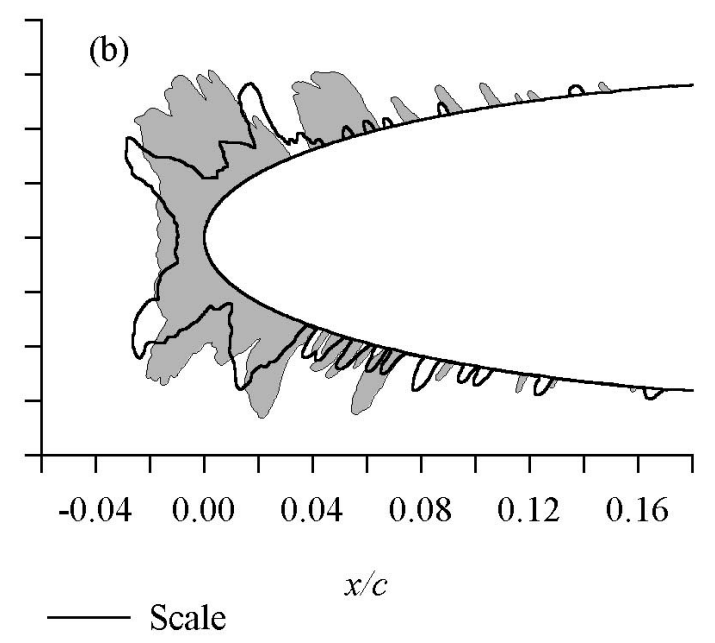

(b) Constant-We method. Scale chord, $53.3 \mathrm{~cm}$.

$$
\begin{aligned}
& \begin{array}{cccccccccccccccc}
\text { Method Date/Run } & c, & t_{s t}, & V, & M V D, & L W C, & \tau, & K_{0} & \beta_{0} & A_{c} & n & b & \phi, & \theta, & R e, & W e, \\
\mathrm{~cm} & { }^{\circ} \mathrm{C} & \mathrm{m} / \mathrm{s} & \mu \mathrm{m} & \mathrm{g} / \mathrm{m}^{3} & \min & & & & & & &
\end{array} \\
& \begin{array}{lllllllllllllllll}
\text { Reference } & 3-7-01 / 5 & 91.4 & -10.4 & 77.4 & 175 & 0.99 & 11.0 & 35.6 & 0.97 & 1.91 & 0.30 & 0.93 & 9.7 & 13.0 & 17.0 & 16.1
\end{array}
\end{aligned}
$$

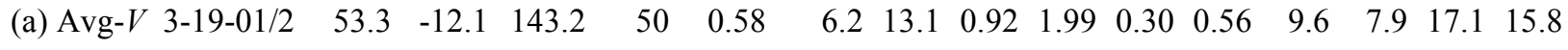

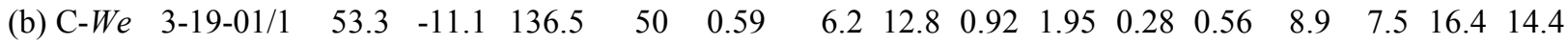

Figure 6. Scaling from 175 to $50 \mu \mathrm{m} M V D$; Freezing Fraction, 0.3; Reference chord, $91.4 \mathrm{~cm}$. Case 225SLD. 
the average- $V$ method and 6(b) for the constant- $W e$ method for the $53.3-\mathrm{cm}$ model.

Both methods of finding scale velocity produced scale shapes that were non-dimensionally smaller than the reference, exhibited horn structures different from the reference and failed to simulate the large feather formations aft of the main reference ice shape. Splashing of impinging droplets might redistribute water on the surface to create significantly different shapes, and, based on the Mundo, Sommerfeld and Tropea ${ }^{3} K$ factor for splashing, splashing would tend to be more significant in the reference tests. However, this explanation is inconsistent with the larger quantity of ice accreted for the $175-\mu \mathrm{m}$ $M V D$. Significant differences in the droplet size distribution for the 175- and 50- $\mu \mathrm{m} M V D$ clouds might also account for the shape disparities, but the distributions reported by Ide and Oldenburg ${ }^{10}$ for the IRT do not reveal such differences. Testing is planned to study scaling from $175-\mu \mathrm{m} M V D$ clouds further.

\section{Conclusions}

- Scaling to Appendix-C conditions from SLD was accomplished successfully for reference $M V D$ 's up to $120 \mu \mathrm{m}$. This result suggests that either splashing does not significantly affect ice shapes for drop sizes up to $120 \mu \mathrm{m}$, or the two scaling methods used in this study already adequately describe splashing phenomena.

- Scaling from $175 \mu \mathrm{m} M V D$ to $50 \mu \mathrm{m}$ was not successful. Because the reference ice shapes were non-dimensionally much larger than the scale, splashing does not seem to be the likely explanation for the dissimilarity. Additional testing is required to identify the cause of the shape differences between scale and reference.

- No evidence of end effects was observed in tests with the partial-span models. Full-span and partial-span models gave consistent ice shapes.

- Both the constant-We and average- $V$ methods of determining scale velocity gave equivalent scaling results.

\section{References}

${ }^{1}$ Bilanin, Alan J. and Anderson, David N., "Ice Accretion with Varying Surface Tension," AIAA95-0538 and NASA TM-106826, January 1995.

${ }^{2}$ Wright, William B., "Computational Simulation of Large Droplet Icing," Proceedings of the FAA International Conference on Aircraft Inflight Icing vol. II, DOT/FAA/AR-96/81,II, August 1996, pp 545555.

${ }^{3}$ Mundo, C., Sommerfeld, M. and Tropea, C., "Droplet-Wall Collisions: Experimental Studies of the Deformation and Breakup Process," Int. J. Multiphase Flow, vol. 21, no. 2, 1995, pp. 151-173.

${ }^{4}$ Ruff, Gary A., "Analysis and Verification of the Icing Scaling Equations," AEDC-TR-85-30, vol. 1 (rev), March 1986.

${ }^{5}$ Messinger, B.L., "Equilibrium Temperature of an Unheated Icing Surface as a Function of Airspeed," J. Aeron. Sci., vol. 20 no. 1, January 1953, pp. 29-42.

${ }^{6}$ Anderson, David N. and Ruff, Gary A., "Evaluation of Methods to Select Scale Velocities in Icing Scaling Tests," AIAA-99-0244, January 1999.

${ }^{7}$ Anderson, David N., "Effect of Velocity in Icing Scaling Tests," AIAA-2000-0236, January 2000.

${ }^{8}$ Irvine, Thomas B. and Anderson, David N., "The NASA Lewis Icing Research Tunnel Testing and Data Acquisition," Proceedings of the FAA International Conference on Aircraft Inflight Icing vol. II, DOT/FAA/AR-96/81,II, August 1996, pp. 469-483.

${ }^{9}$ Anderson, David N., "Acceptable Tolerances for Matching Icing Similarity Parameters in Scaling Applications," AIAA-2001-0832, January 2001.

${ }^{10}$ Ide, Robert F. and Oldenburg, John R., "Icing Cloud Calibration of the NASA Glenn Icing Research Tunnel," AIAA-2001-0234, January 2001.

${ }^{11}$ Irvine, Thomas B., Kevdzija, Susan L., Sheldon, David W. and Spera, David A., "Overview of the Icing and Flow Quality Improvements Program for the NASA Glenn Icing Research Tunnel," AIAA2001-0229, January 2001.

${ }^{12}$ Coleman, Hugh W. and Steele, W. Glenn, " $E x$ perimentation and Uncertainty Analysis for Engineers," John Wiley \& Sons, 1989. 


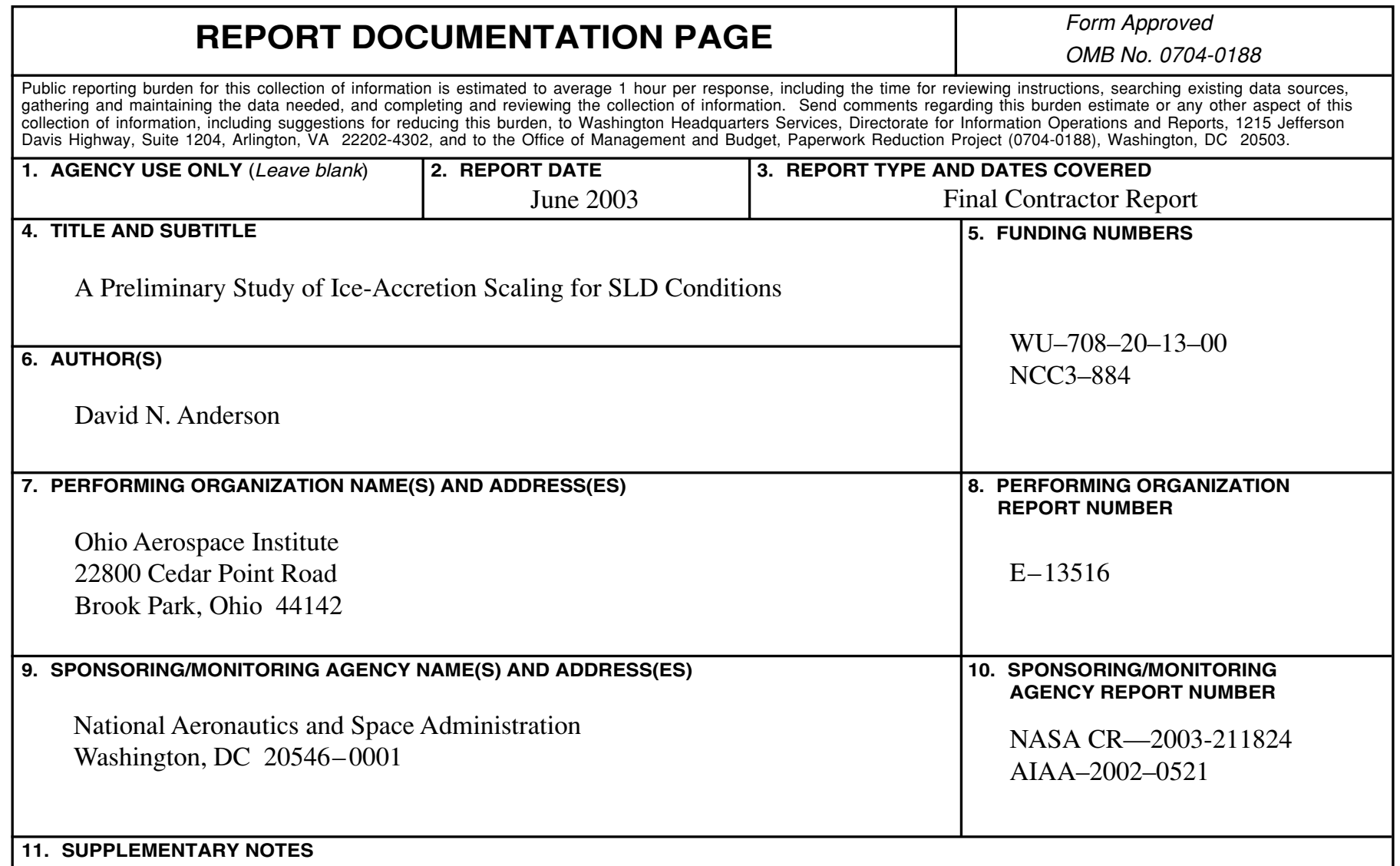

Prepared for the 40th Aerospace Sciences Meeting and Exhibit sponsored by the American Institute of Aeronautics and Astronautics, Reno, Nevada, January 14-17, 2002. Project Manager, Thomas H. Bond, Turbomachinery and Propulsion Systems Division, NASA Glenn Research Center, organization code 5840, 216-433-3900.

12a. DISTRIBUTION/AVAILABILITY STATEMENT

12b. DISTRIBUTION CODE

Unclassified - Unlimited

Subject Category: 02

Distribution: Nonstandard

Available electronically at http://gltrs.grc.nasa.gov

This publication is available from the NASA Center for AeroSpace Information, 301-621-0390.

13. ABSTRACT (Maximum 200 words)

Proposed changes to aircraft icing certification rules are being considered by European, Canadian, and American regulatory agencies to include operation in super-cooled large droplet conditions (SLD). This paper reports results of an experimental study in the NASA Glenn Icing Research Tunnel (IRT) to evaluate how well scaling methods developed for Appendix C conditions might apply to SLD conditions. Until now, scaling studies have been confined to the FAA FAR-25 Appendix $\mathrm{C}$ envelope of atmospheric cloud conditions. Tests were made in which it was attempted to scale to a droplet $M V D$ of $50 \mu \mathrm{m}$ from clouds having droplet $M V D$ s of 175, 120, 100, and 70 $\mu \mathrm{m}$. Scaling was based on the Ruff method with scale velocities found either by maintaining constant Weber number or by using the average of the velocities obtained by maintaining constant Weber number and constant Reynolds number. Models were unswept NACA 0012 wing sections. The reference model had a chord of $91.4 \mathrm{~cm}$. Scale models had chords of 91.4, 80.0, and $53.3 \mathrm{~cm}$. Tests were conducted with reference airspeeds of 100 and $150 \mathrm{kt} \mathrm{(52} \mathrm{and} 77 \mathrm{~m} / \mathrm{s})$ and with freezing fractions of 1.0, 0.6, and 0.3. It was demonstrated that the scaled $50-\mu \mathrm{m}$ cloud simulated well the non-dimensional ice shapes accreted in clouds with MVD's of $120 \mu \mathrm{m}$ or less.

14. SUBJECT TERMS

Aircraft safety; Aircraft icing; Super-cooled large droplet icing; Icing scaling 15. NUMBER OF PAGES 16

\begin{tabular}{|c|c|c|}
\hline $\begin{array}{c}\text { 17. SECURITY CLASSIFICATION } \\
\text { OF REPORT } \\
\text { Unclassified }\end{array}$ & $\begin{array}{c}\text { 18. SECURITY CLASSIFICATION } \\
\text { OF THIS PAGE } \\
\text { Unclassified }\end{array}$ & $\begin{array}{c}\text { 19. SECURITY CLASSIFICATION } \\
\text { OF ABSTRACT } \\
\text { Unclassified }\end{array}$ \\
\hline
\end{tabular}

